K eineswegs! "Eher glaube ich daran, daß Esel fliegen können, als ein Mönch lügt." Das sagte Thomas von Aquin in einer bekannten Anekdote aus seinem Leben. Ähnlich denke ich auch in Bezug auf vermeintliche Fehler der Großen.

Nichtdestotrotz pflege ich in solchen Fällen, nach Lust und Laune der Sache nachzugehen und ein einzelnes Wort auf Nieren und Blut zu prüfen. Ein großer Zeitverlust tatsächlich, aber, wie man heute sagt, eine leistungsstarke Methode, eine Fremdsprache etwas besser zu verstehen.

Hinzufügen möchte ich auch, daß die spanische Übersetzung eines deutschen Werkes nicht unbedingt falsch sein muß, doch in der Regel finden wir leider allzu oft "trapos por harapos" und noch Schlimmeres. Das ist eine Feststellung, die Gegenstand einer seriöseren Arbeit sein sollte.

Das Wort 'Ufer' ist heute in der Bedeutung von "Begrenzung eines Gewässers durch das Festland" zu verstehen (Duden Bedeutungswörterbuch 1970) des', doch liegt diese Annahme semantisch nicht nahe." (Kluge 1989)

Im Bereich der romanischen Sprachen treffen wir sp. 'costa' und afrz. 'coste' (frz. 'côte'). Das französische Wort bedeutet eigentlich 'Rippe', dann 'Seite', dann 'Küste'. Die lateinische Sprache hatte für 'Küste' 'ora, -ae', 'litus, -oris', 'ripa, -ae' und 'acta, -ae', aus denen sp. 'orilla', 'litoral', 'ribera' stammen. (Diccionario llustrado Latino-Español, Español-Latino Spes 1964)

Was noch sympathischer vorkommt, ist die Tatsache, daß 'el vino de la ribera del Duero' mit 'la chuleta de Ávila' und 'las barbas del profeta' auf Deutsch eigentlich sprachliche Gemeinsamkeiten hat. Denn I. 'ripa' > dt. 'Rippe'/'Rippenstück' = 'Kotelett' (sp. 'chuleta', aber auch mit sp. 'ribera'/'costa'/'costilla' und frz. 'côte'/'côtelette' verwandt). Nun "Koteletten 'Backenbart' ('patillas') ist eine scherzhafte Übertragung aus Berlin, wo man mit Haarkoteletten die Form bestimmter Backenbärte kommentierte." (Kluge 1989)

\title{
¿HÖLDERLIN SUSPENDE EN GEOGRAFÍA?
}

bzw. "Rand eines Gewässers." (Duden Stilwörterbuch 1970) Nach meinem Ermessen wird das Wort umgangssprachlich in Zusammenhang mit Binnengewässern und Flüssen gebraucht, doch es ist auch nicht selten, es in Verbindung mit Meeren und Ozeanen zu finden. 'Küste' wird als 'Meeresufer' beschrieben. (Duden 1970). So ist nunmal der Sprachwandel.

'Ufer' geht auf wg. *ôbera zurück und ist mit spmhd. uover, mndd over, mndl. oever und ae. ofer verwandt. Außergermanisch finden wir gr. 'êpeiros mit der Bedeutung 'Küste'. "Ähnlich ist arm. ap'n 'Ufer', das aber lautlich nicht genau dazu stimmt. Vielleicht zu ai. ápara- 'hinterer, späterer' als 'Dahinterliegen-
Bis zum 17. Jh. war 'Ufer' auch das Wort für 'Küste', das zu dieser Zeit aus dem Französischen entlehnt wurde. (Kluge 1989) Hölderlins Werk erschien 1797 Manuel Osuna Muñoz 1799 in zwei Bänden. Das Wort E.O.I. de Cáceres verdrängt zu werden. 'Ufer' hatte also Zeit genug gehabt, in bestimmten Kontexten von dem Term 'Küste'

Hölderlin kann man sicherlich eine 'gewisse' Sprachbeherrschung unterstellen. Nehme ich an! 'Ufer', 'Gestade', 'Küste', ... 'Rand', 'Saum', ... 'Brandung', 'Strand', ... hätte unser in Landeskunde nicht bestandener Autor zu Verfügung gehabt. Der Tor wählte 'Ufer' zu seinem Unglück.

Das Deutsche behält noch vieles von dem Wurzel- 


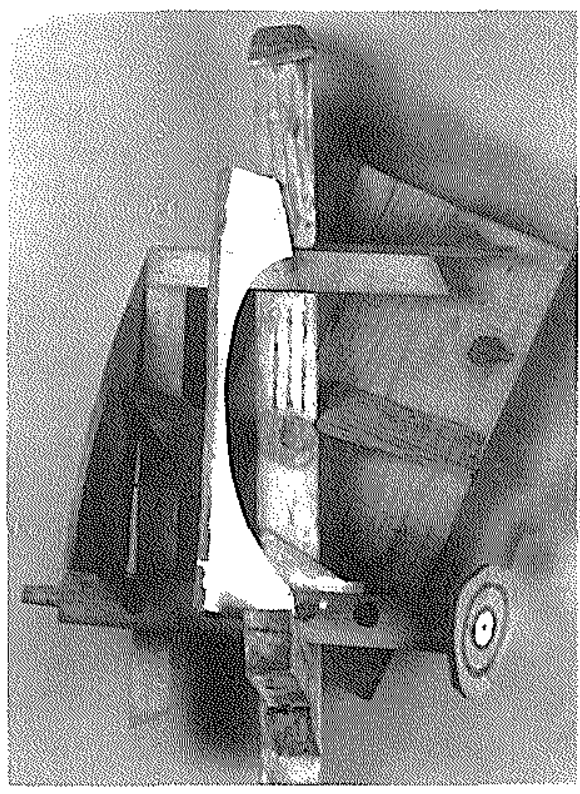

sprachentypus. Zu Zeiten Hölderlins jagten Scharen Philologen nach Wurzeln, deuteten sie, stellten eine ganze Reihe Bedeutungsnuancen sicher, trugen schließlich dazu bei, daß in kaum fünfzig Jahren aus nicht genormten Variationen von Dialekten eine Kultursprache mit Nationalliteratur entstand.

Wörter haben einen Hof wie der Mond. Im Kontext treten sowohl die Bedeutung als auch eine Verflechtung von evozierenden Nebenbezeichnungen zu Tage. Das kann der Anfang eines Bildes sein.

Merkwürdig an dem Satz ist der Gebrauch von 'Ufer' in Verbindung mit 'Sevilla'. Eine Stadt hat jedoch kein Ufer, denn es ist das Gewässer, was Ufer hat. Diese syntagmatische Seltenheit bringt mich zur Interpretierung des Wortes 'Ufer' auf die offene Bedeutung des griechischen Wortes 'êpeiros' "(por oposición al mar) tierra firme; tierra interior" (Diccionario Manual Griego-Español, José Maria Pabón 1968). Demnach ist er nach dem Schiffbruch ans Festland von Sevilla angelangt, dadurch gerettet. Hamburg als Hafenstadt liegt in Fluglinie ca. $80 \mathrm{Km}$ von der Nordseeküste entfernt. Sevilla genau so von der Einmündung des Guadalquivirs bei Sanlúcar de Barrameda. Kein ausländischer Dichter käme auf die Idee, seinen Held 'am Ufer von Buxtehude' retten zu lassen.

Die dichterische Freiheit ist hier gefragt, denn Sevi-
Ila ist die sagenumwobene Stadt an der Peripherie. Ob die "exzentrische Bahn" als Bild des menschlichen Schicksals - denn das Individuum strebt danach, von der Einheit allen Lebens abzufallen, sucht den eigenen Mittelpunkt und möchte sich verselbständigen, was die umfangende Natur an sich nicht erlaubt - sich hier in der Form einer gescheiterten Schiffreise widerspiegelt, ist vielleicht zu abwegig. Doch die Literatur ist ständig von diesen kleinsten Teilchen verdichtet und gleichzeitig von Genauigkeiten befreit. Wie sonst darf sich der Geist von Bildern und Vorstellungen treiben lassen?

Ich erinnere mich an die Worte von Ortega y Gasset: "Ich lese nicht, um zu sehen, wie sich bei jedem Satz die Regeln der Grammatik bestätigen lassen; ich lese, um mein Herz zu erweitern."

Wir sind trotzdem der Philologie und ihren wissenschaftlichen Verfahren verpflichtet. Denn selbst Ortega y Gasset empörte sich kritisch anderswo über die Methode, Dichtung mit noch mehr Dichtung zu analysieren.

Hölderlin -das wissen wir heute (Friedrich Hölderlin, Pierre Bertaux 1978, 113)- war ein bewußter Übersetzer der griechischen Klassik. Er beherrschte von Ausbildung her Latein und Griechisch und -wie Theodor Schwab berichtet- "sprach italienisch, ohne daß man wüßte, wo und wann er die Sprache erlernt hätte." (Pierre Bertaux 1978, 325). Ich erinnere mich
Pablo Picasso, escultura,"Mandolina y clarinete", 1913
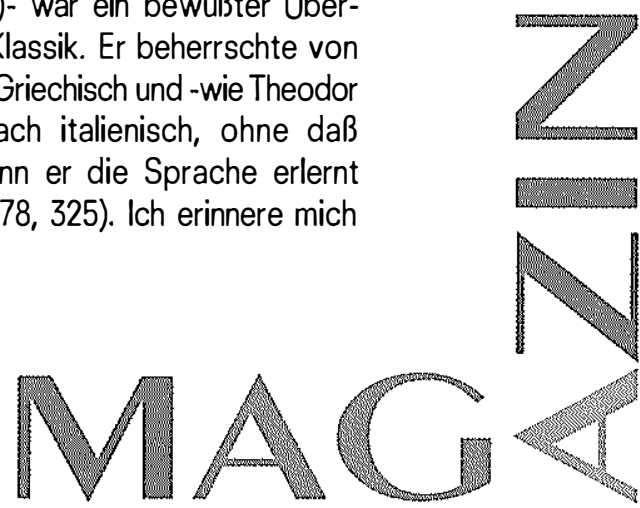
noch, irgendwo mal gelesen zu haben - ich kann es aber nicht mehr feststellen-, daß Hölderlin auch von der spanischen Literatur (nachweisbar!) beinflußt wurde. Das war übrigens zu dieser Zeit keine Seltenheit, und ich weigere mich hierfür, meinen Zettelberg durchzuwühlen. Leichteres wäre zum Gegenteil für interessierte Kritiker, die Kapitel in Pierre Bertaux oben zitiertem Buch zu lesen: "Die Welt der Töne", "Die Stimme", "Das Wort", "Die Sprache" und "Eidetisches, nichtlineares Denken". Aber zu Gunsten meiner oben etablierten Hypothese erlaube ich mir, einige Stellen zu zitieren.

"(...) Diese ethymologische Erneuerung der Sprache hat Hölderlin methodisch verfolgt, und nicht nur aus eigenem, spontanen Antrieb: sie ist ein Zug der Zeit, einer Zeit, die der Ethymologie manchmal sogar leichtsinnig nachging; eine Mode, über die sich Goethe im Gedicht 'Ethymologie' lustig machte. (...) So ist die Lektüre von Zuberbühlers glänzenden Essay die allerbeste Einführung, die man sich denken kann, in die eigenartige Sprache Hölderlins. Um seine Lyrik voll genießen zu können, muß man allerdings diese Sprache fast wie eine Fremdsprache erlernen. Doch wirkt sie einzig und allein dadurch befremdend, daß wir nicht mehr gewöhnt sind, den Ursprung der Worte zu erkennen." $(247,248)$

Man kann sich ein Bild von dem laufenden Gewühl jener Zeit machen, wenn wir einen Brief Blanco Whites an den Rektor des Priesterseminars zu Sevilla lesen. Dort empfiehlt der im englischen Exil lebende Autor, die griechische Sprache in die Studienpläne einzuführen, denn nur mit Latein reiche die Ausbildung eines aufgeklärten Menschen in Europa nicht aus.

Zum Glück hat unser in Geographie hoch gebildeter Leser das Original nicht gelesen. Was hätte er sonst noch von der miserablen Rechtschreibung Hölderlins sagen können?

Sierra de Fuentes 18.08.1997

M.O.M

\section{ZWEI LEKTÜRETIPS:}

PETER KOCH/ГHOMAS KREFELD/WULF Oesterreicher (1997):

Neues aus Sankt Eiermark: das kleine Buch der Sprachwitze. München: Beck, 1997 (Beck'sche Reihe; 1187).

ISBN 3406392873

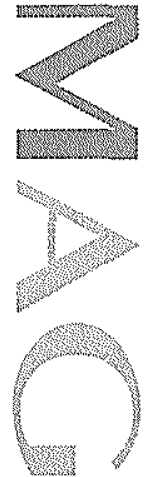

WOLFGANG BALK / SEBASTIAN KLEINSCHMIDT (Hrsg.) (1993):

"Denk ich an Deutschland ..." Stimmen der Befremdung. Fischer Taschenbuch, Frankfurt, ISBN: 3-596-11838-7. 